\title{
A computerised examination system
}

\author{
Teemupekka Virtanen, Ronja Addams-Moring, Sanna Liimatainen and Linda \\ Staffans \\ University of Oulu, Finland and the Department of Education, South Africa
}

\begin{abstract}
Due to large numbers of students and shortage of resources we have been positively encouraged to make examinations and their management more efficient. We have built a system that can be used for computerised examinations and have had a mostly positive experience with it over several years. With this system students can sign up for the examination, write their answers in the computer class and afterwards get their results by e-mail. For administrators it offers the possibility to get the list of participants, apportion the answers to several persons for grading, automatically combine the results and get the distribution of them, define the limits for grades, transfer the results almost automatically to the study register and send the results personally to the students. There has been one serious incident of cheating thus far. The case, its investigation and the lessons learned are presented in this paper too.
\end{abstract}

Key words: computerised examination, university education, cheating

\section{BACKGROUND}

The Telecommunication Software and Multimedia Laboratory is approximately seven years old (www.tml.hut.fi). It is a part of the Department of Computer Science and Engineering (www.hut.fi) at Helsinki University of Technology. During these past seven years the laboratory has become the most popular choice for a major course among the undergraduate students of the department. The rapid increase of students has caused a shortage of resources as the laboratory budget seems to always grow at a slower rate than the number of students.

The laboratory has several courses, each with 200 to 400 participants (T250, T300, T350, T400, T401). These courses form the basis of all our

The original version of this chapter was revised: The copyright line was incorrect. This has been corrected. The Erratum to this chapter is available at DOI: 10.1007/978-0-387-35615-0_52 
laboratory majors. The effective management of these courses is essential for the economy of the laboratory because the university has set a limit to how much a course may, on average, cost per student.

The laboratory uses a lot of temporary staff, both as lecturers and as assistants. Many of the courses are served by experts from the industry. A head assistant, usually a student working part time at the university, manages the administrative work and is a team leader for the other assistants. The examinations are graded as group work, led by the lecturer.

\section{PROBLEMS}

When handling an examination with as many as 400 participants and up to ten grades, there are three main problems: efficient management, distributed grading, and hard-to-read handwriting.

When managing an examination there are only two 'intelligent' work phases: grading the answers, and deciding the limits for the grades. All the other phases (point summarisation, grade calculation, etc.) can be automated if the points for each answer are stored in a data base.

The university requires that examinations must be graded in four weeks. The original examination answers may not be taken away from the laboratory. It is often difficult to find suitable times for the visiting lecturer and part-time assistant(s) to sit together to grade the examinations within the time limit. If the lecturer grades only one question and if there are, say, 400 answers, it may require 20 hours of work; even more if the question is an essay with several pages of writing per student.

Handwriting is a practical problem; if one wants to grade several hundred essay-type answers, there is no room for unclear handwriting. In one's mother tongue it is possible to read bad handwriting quite fast, but in a foreign language the work becomes much slower.

\section{THE COMPUTERISED EXAMINATION SYSTEM}

\subsection{The goals}

The goal was to create a system, which automates common actions and helps in repeated procedures. It would not only reduce the routine work of the staff but also help students to do their work more easily (Seppä, 2000).

Our courses and curriculum are changing fast. The system must be able to adapt to, for example, new methods for examinations. The staff rotation is 
fast, too. The system must be able to support these changes and it must be easy for new employees to learn to use it.

The main goal of this system was to get the answers of an examination into electronic form. It must be possible to store and grade the answers electronically, combine the results of single answers to a grade and to forward the results. Also, it must be possible to apportion the grading work among several people.

Security is an important issue. Some students will always try to cheat in examinations, so the system must be able to prevent 'e-Cheating'. Also, the results of the examinations are very important for students and they have to be stored and managed very carefully.

\subsection{The student's view}

At the beginning of a course students must sign up for it. As part of the enrolment data, an e-mail address and a pgp public key are stored. The identity of the student is checked when the key is signed and stored in the data base.

For each examination some classrooms with workstations are reserved. Each workstation is equipped with a WWW-browser. As there is only a limited number of workstations, students have to enroll for the examination. There is usually the option to take the examination 'traditionally' on paper, too.

When arriving at the classrooms students have to prove their identity and mark themselves as present, after which they are given the password for that examination. It is possible to arrive within one hour after the beginning of the examination. During this time nobody is allowed to leave the classroom(s).

The workstations are multi-purpose networked workstations and no programs or files are removed from them. To prevent cheating we require and see that only one window is open on each workstation. This window must fill the whole screen and it is used by the WWW-client. The only server allowed is the examination server.

At the beginning of the examination each student has to log on to the system using her or his student number and the examination password. The password is naturally different for each examination.

After a successful login the student gets a form containing the examination. There are typically several questions on the form. The student may answer the questions in any order. After finishing an answer the student accepts the answer and it is stored in the data base. The student may return to any of the questions and change her/his answer repeatedly if (s)he wishes. 
When the examination is completed and the student is ready to leave (s)he starts the finalisation script using a special button on the form. This script shows the whole examination once more and the student has to accept it. After that the student may leave the examination.

\subsection{The staff view}

The server is a standard apache WWW-server in a Sun server. The server consists of, basically, a simple data base, the examination form and several scripts. The access to this server is restricted for a pre-defined time interval and it is additionally protected, among other techniques, with an access list and with a password, which is different for each examination.

We have an examination master administrator who is in charge of the computerised examinations. After the course lecturer and head assistant have defined the questions, (s)he formats the question forms for each language version, opens the server for the examination, oversees the activities on the server during the examination and closes the examination afterwards. As this work is time critical, there are one or two back-up people, too.

On the examination day, each workstation classroom has an examination supervisor. (S)he has the list of enrolments and checks the identity of the students when marking them present. The supervisor also gives the participants the examination password. During the examination (s)he stays in the back of the classroom to observe the screens to ensure that there are no other connections or windows open.

After the examination the course head assistant sends the grading criteria via e-mail to the members of the course team. The grading work can be done on-line (naturally, the connections are protected) or, in some cases, the answers are sent to a grader as encrypted e-mail.

When all the questions have been graded the head assistant checks the results of the examination (average, distribution, etc.). The system suggests point limits for the different grades but the final decision is, naturally, the lecturer's. After the system has graded the examinations the results are sent to the central study data base of the university and the system automatically sends each student her or his own result as an e-mail.

\section{EXPERIENCES}

In principle the computerised examination is a worthwhile idea. It has been used for some five years for at least 50 examinations. There have been three main administrators and several assistants who have updated the data, too. 
The experiences have been positive and the main goals have been achieved. It is much faster to read answers from a screen or a printout than from handwritten paper and it has been possible to grade the examinations, for example, at home. We have divided the grading duty among the staff. This requires common grading criteria, which must be very clearly written. The criteria are published for the students, too, together with the examination results. We have found that this greatly reduces the number of questions and complaints about the examination.

There have been many practical problems with the system. The examinations tend to be at the end of terms. There is a long period without examinations and then many examinations in a short time. The first examination in a row is always at risk. There have always been some changes in the environment that require modifications in the examination system. So we always keep the option to switch over to the paper examination. The limited amount of workstations is a serious problem. We have the capacity for about 100 students to participate in a computerised examination. Any additional students must take a 'traditional' examination on paper.

\section{THE INCIDENT}

There has so far been only one serious incident of cheating. It happened before we introduced the use of the one-time examination passwords.

\subsection{The suspicion}

After this examination, when the master administrator (MA) closed the examination she noticed that there was one unclosed session and its answer file was empty. The session belonged to student id-number X. She called the course head assistant (HA), who verified that student $X$, whom she knew, had not been in the building where HA had overseen the examination. They could not reach the examination supervisor (ES) of the other building right away. At this point MA and HA assumed some weird technical problem or gross error by the student in using the examination form.

HA then received the other building's examination attendance lists. $X$ had signed up for the examination but there was no signature by the name $\mathrm{X}$, so it had to be assumed that $X$ had not participated in the examination. When HA reached ES, they concluded that $X$ had not been present in any of the examination classrooms - they both knew $\mathrm{X}$ and had personally checked the identities of every student who attended. So, the possibility of cheating had to be considered, even though cheating should have been impossible. 
MA then fine-combed the log files and double-checked everything about the examination. She found an error in the examination server's access list: some of the IP-addresses that should have been blocked were actually allowed. Also, there had been a connection to the examination server from such an IP-address. So we had reason to suspect cheating and thus an obligation to investigate.

\subsection{The investigation}

There were two starting points for the investigation - the unclosed session and the unauthorised connection in the log file. The unclosed session pointed to $\mathrm{X}$. But $\mathrm{X}$ had not taken the examination, so $\mathrm{X}$ could not benefit from the possible cheating. Could X have been helping someone - or had X been framed? Some of the homework assignments in this course were done in small groups and there was one other student $(Y)$ who had returned some assignments together with $\mathrm{X}$ and thus knew $\mathrm{X}$ 's id number. Student $\mathrm{Y}$, whom HA also knew, came to the examination at the very end of the first hour, which was not typical examination behaviour of Y. So, we had at least one additional suspect.

The unauthorised connection came from a computer which was owned by the university's computing centre (CC). We could only see the IP number, name and the location of that computer from the public documentation, but we had no access to its internal logs. It was located in a classroom, which was accessible to all students and all staff of the whole university at the time of the suspect connection. So after taking the decision to investigate, the CC was contacted. Due to privacy protection reasons they could not reveal anything without proper official documents but they immediately started an internal investigation and ensured that no evidence was accidentally destroyed. After some bureaucratic needs had been fulfilled, they reported their findings: during the time in question there was a connection from the named computer to the examination server. At that time someone using Y's user-id, presumably student $\mathrm{Y}$, was logged on to that computer. The user had also made a print job. The contents of the print job could not be revealed for privacy reasons but the name of the job was the same as the header of the examination page.

\subsection{The judgment}

There was no evidence against $X$ and therefore $X$ was acquitted. There was evidence against $Y$; however, it was unclear if the evidence against $Y$ was strong enough. Therefore, an encrypted e-mail was sent to $\mathrm{Y}$ describing 
the situation and asking $\mathrm{Y}$ to come and explain. Otherwise we would have to assume that $Y$ had cheated, and take proper action. The student never came.

After this the case against $Y$ was handled according to department rules pertaining to cheating (see web-site www.cs.hut.fi).

\subsection{The lessons}

The first lesson is obvious: cheating should not have been possible within the technical environment. However, it was. There were technical precautions, but an oversight is always possible. Since this incident the number of technical precautions has been increased.

The second lesson is maybe even more important and, at times difficult to put into practice well. It could be called 'well-defined procedure and constant vigilance'. Our staff is used to various problems during the computer examinations and this may dull our alertness if we are confronted with a (non-obvious) cheating attempt. After this incident the rules for handling 'strange' situations have been clarified, with special attention given to documentation. Basically, an examination supervisor must, if anything seems odd, document everything about the situation and double-check with either HA or MA before deciding how to proceed.

The third lesson has to do with work morale, specifically perseverence with dull routine tasks. The computer examination system produces a lot of logs, and reading them can be frustrating. However, when they are needed they are immensely valuable. Today the logs are followed even more carefully during an examination and double-checked afterwards.

\section{FURTHER DEVELOPMENT}

The number of workstations is too small for examinations for several hundred students. If relatively few students use computers and most of the answers come on paper, the gain from using computers is relatively small. As we cannot offer several hundred workstations for an examination, another solution is being considered. It may be possible to use wireless networks because many of the students have their own laptop computers and WLAN.

We have also considered using the existing PGP-infrastructure for the finalisation script with which the students return their examinations.

It would be useful if the system supported workflow management. The user interface and stability of the administration system are not as good as they should be, either. We are computer specialists and can use the system with scanty documentation as we can always read the source code. But a better user interface can rationalise work and prevent errors. 


\section{CONCLUSIONS}

The TM-laboratory has applied new technology to examination administration in view of the increased number of students and shortage of resources. For that purpose a system for computerised examination has been developed. This system has been used for some five years and for at least 50 examinations. It has fulfilled most of our expectations, but the mixture of computer and paper examinations reduces many of the advantages.

There has been one serious case of cheating. Computers give new possibilities for cheating, and systems and procedures have to be designed and maintained carefully to avoid this.

\section{REFERENCES}

Seppä, M. (2000) The requirements for the New Learning Systems and How the TML

Learning Systems Stand Up in Comparison. Master's Thesis. Helsinki University of

Technology, Finland

Web-site references

http://www.hut.fi/English/ (Helsinki University of Technology)

http://www.cs.hut.fi/u/ssurakka/tiedotus/cheating.html (cheating)

http://www.tml.hut.fi/Studies/T-110.250/ (course T-250) (and similar references for courses

T-300, T-350, T-400 and T-401)

http://www.hut.fi/Yksikot/Tieto/uusinde.htm (Department of Computer Science and

Engineering)

http://www.tml.hut.fi/english.html (Telecommunications Software and Multimedia

Laboratory)

\section{BIOGRAPHIES}

All the authors work at the Telecommunication Software Laboratory at the Helsinki University of Technology. Teemupekka Virtanen is the professor of telecommunication software, Sanna Liimatainen is a researcher and Ronja Addams-Moring and Linda Staffans are research assistants. 